\title{
Introduction to this Special Issue
}

\author{
Jorge A. Capote and Daniel Alvear*, GIDAI Group, University of Cantabria, \\ Santander, Spain
}

Over the last ten years, GIDAI Group (University of Cantabria, Santander-Spain) has organized different International Technical Congress and Journals on Fire Safety. During the last five years, there has been one annual International Congress. The focus of the conferences was to bring together the world's leaders in Fire Safety Engineering.

On October 15-17 2008 the International Congress "Smoke Control in Buildings and Tunnels" took place at the University of Cantabria. The aim of the Congress was to bring together numerical and experimental practitioners in smoke dynamics, and foster discussion and exchange of knowledge about the principal innovations and advanced technologies of smoke control in buildings and tunnels. Experts in the field were called upon to present their research, applications and case studies to a worldwide audience. The programme covered both theoretical and practical aspects.

Twenty-four (24) selected Papers were presented to the International Congress, representing different countries (USA, UK, Canada, China, France, Japan, Portugal, Italy, Belgium, Sweden, Spain, etc.).

Congress Chairmen wanted to express special recognition for the work developed in the selection of the papers to the Scientific Committee of the International Congress, integrated by the out-standing Professors and Researches-Dr. Jorge A. Capote (GIDAI-University of Cantabria-Spain), Dr. Daniel Alvear (GIDAI-University of Cantabria-Spain), Dr. Richard Carvel (University of Edinburgh-UK), Dr. Wan-Ki Chow (Hong Kong Pol. University-China), Dr. Carlos Fernández Pello (University of California, Berkeley-USA), Dr. Charles M. Fleischmann (University of Canterbury - N. Zealand), Dr. George V. Hadjisophocleous (University of Carleton-Canada), Mr. Morgan J. Hurley (SFPE-USA), Dr. James A. Milke (University of Maryland-USA), Dr. Frederick W. Mowrer (University of Maryland-USA), Dr. Marcelo Reggio (École Pol. Montréal - Canada), Dr. Guillermo Rein (University of Edinburgh-UK), Dr. José L. Torero (University of Edinburgh-UK) and Dr. Arnaud Trouve (University of Maryland-USA), whose scientific - contribution has allowed to reach a International Congress with the highest quality.

We also want to express our gratitude to the authors and speakers who have dedicated their time and effort to bring us their presentations, experience, methodologies and scientific-technical advances in the Smoke Control.

\footnotetext{
* Correspondence should be addressed to: Daniel Alvear, E-mail: alveard@unican.es
} 
This issue contains six of the best Smoke Control Papers from the International Congress "Smoke Control in Buildings and Tunnels". They have been enhanced and subjected to the regular peer review process of the Conference. 